\title{
Escritos de Thereza Pereira Rocha: de Pestalozzi à Thorndike, saberes para ensinar problemas aritméticos
}

\author{
Bruna Lima Ramos Giusti ${ }^{1}$ \\ Andreia Fernandes de Souza ${ }^{2}$
}

\begin{abstract}
RESUMO
Esse artigo propõe observar as sistematizações na constituição do saber profissional, com base nas de apropriações feitas por Thereza Pereira da Rocha, em seu caderno datado do ano de 1958, no qual registrou anotações de um curso de aperfeiçoamento. Utilizaram-se como metodologia os seguintes conceitos: processos (BURKE, 2016), saberes profissionais (HOFSTETTER; SCHENEUWLY, 2017) e, mais próximo desse objetivo teórico, os conceitos de matemática a ensinar e matemática para ensinar (BERTINI; MORAIS; VALENTE, 2017). Entende-se que os saberes registrados no caderno remetem a preceitos anteriores à produção desse documento, mais especificamente a dois autores: Pestalozzi e Thorndike. O primeiro autor marca a disseminação do método intuitivo nos anos finais do século XIX, no Brasil. O segundo, a partir dos avanços a respeito do desenvolvimento infantil, propõe mudanças em relação ao ensino de aritmética no início do século XX. Como conclusões, indica-se que no caderno há preceitos difundidos por esses autores, o que representa que o ensino de aritmética não descartou simplesmente ideias anteriores e, sim, incorporou-as no ensino dito "moderno".
\end{abstract}

PALAVRAS-CHAVE: Caderno escolar. História da Educação Matemática. Saber Profissional. Problemas Aritméticos.

\footnotetext{
1 Doutora em Ciências. Universidade Federal de São Paulo, Guarulhos, São Paulo, Brasil. Orcid: https://orcid.org/0000-0002-5561-868X. E-mail: bruna_lramos@hotmail.com.

2 Mestra em Ciências. Universidade Federal de São Paulo, Guarulhos, São Paulo, Brasil. Orcid: https://orcid.org/0000-0002-5429-0280. E-mail: deianandes@ hotmail.com.
} 
Thereza Pereira Rocha's writings: from Pestalozzi to Thorndike, knowledge to teach arithmetic problems

\begin{abstract}
This article proposes to observe the systematizations in the constitution of professional knowledge, based on those of appropriations made by Thereza Pereira da Rocha, in her notebook dated 1958, in which she recorded notes of an improvement course. The following concepts were used as methodology: processes (BURKE, 2016), professional knowledge (HOFSTETTER; SCHENEUWLY, 2017) and, closer to this theoretical objective, the concepts of mathematics for teaching and mathematics to teach (BERTINI; MORAIS; VALENTE, 2017). It is understood that the knowledge recorded in the notebook refers to precepts prior to the production of this document, more specifically to two authors: Pestalozzi and Thorndike. The first author marks the dissemination of the intuitive method in the final years of the 19th century in Brazil. The second, based on advances in child development, proposes changes in relation to the teaching of arithmetic in the early 20th century. As conclusions, it is indicated that in the notebook there are precepts spread by these authors, which means that the teaching of arithmetic did not simply discard previous ideas, but incorporated them into the so-called "modern" teaching.
\end{abstract}

KEYWORDS: School notebook. History of Mathematics Education. Professional Knowledge. Arithmetic Problems.

Los escritos de Thereza Pereira Rocha: de Pestalozzi a Thorndike, saberes para enseñar problemas aritméticos

\title{
RESUMEN
}

Este artículo propone observar las sistematizaciones en la constitución del saber profesional, a partir de las apropiaciones realizadas por Thereza Pereira da Rocha, en su cuaderno de 1958, en el que registró notas de un curso de perfeccionamiento. Se utilizaron como metodología los siguientes conceptos: procesos (BURKE, 2016), conocimiento profesional (HOFSTETTER; SCHENEUWLY, 2017) y, más cerca de este objetivo teórico, los conceptos de matemáticas para enseñar y matemáticas a enseñar (BERTINI; MORAIS; VALENTE, 2017). Se entiende que los conocimientos registrados en el cuaderno se refieren a preceptos anteriores a la producción de este documento, más 
específicamente a dos autores: Pestalozzi y Thorndike. El primer autor marca la difusión del método intuitivo en los últimos años del siglo XIX en Brasil. El segundo, basado en los avances en el desarrollo infantil, propone cambios en relación con la enseñanza de la aritmética a principios del siglo XX. Como conclusiones se indica que en el cuaderno hay preceptos difundidos por estos autores, lo que significa que la enseñanza de la aritmética no simplemente descartó ideas anteriores, sino que las incorporó a la enseñanza llamada "moderna".

PALABRAS CLAVE: Cuaderno escolar. Historia de la educación matemática. Saber profesional. Problemas aritméticos.

$$
* * *
$$

\section{Introdução}

Buscar, preservar, higienizar, catalogar, submeter ao Repositório de Conteúdo Digital $(\mathrm{RCD})^{3}$, ler e analisar documentos são algumas etapas norteadoras do trabalho de pesquisa do Grupo de História da Educação Matemática no Brasil (GHEMAT). Por meio de um Projeto Temático ${ }^{4}$ de nível nacional, o GHEMAT propõe investigar os saberes profissionais, pesquisando documentos escolares.

Assim, a partir desses documentos ${ }^{5}$, inseridos no RCD, utilizados como fontes em pesquisas acadêmicas, este artigo procura enfatizar como o ensino de problemas aritméticos para o curso primário, no final da década de 1950, pode ter sido fundamentado em autores de manuais pedagógicos do começo do século XX.

\footnotetext{
${ }^{3}$ O RCD se constitui como uma base de dados, alocada nos servidores virtuais da Universidade Federal de Santa Catarina (UFSC). Segundo Giusti, Godoi e Costa (2020), é uma plataforma digital, de livre acesso ao público e pesquisadores, administrado e alimentado pelos membros do Grupo de História da Educação Matemática no Brasil (GHEMAT). "É uma base de dados on-line que reúne, de maneira organizada, documentações históricas obtidas em acervos brasileiros, como também as produções dos integrantes do GHEMAT (artigos, dissertações e teses)" (2020, p. 3). O acesso pode ser feito pelo link: https://repositorio.ufsc.br/handle/123456789/160300.

${ }^{4} \mathrm{O}$ Projeto Temático intitulado "A matemática na formação de professores e no ensino: processos e dinâmicas de produção de um saber profissional, 1890-1990", de autoria de Valente et al. (2017), possui financiamento da Fundação de Amparo a Pesquisa do Estado de São Paulo (FAPESP). Processo n. 17/15751-2, com vigência entre 01 de dezembro de 2017 e 30 de novembro de 2022.

${ }^{5}$ Entre esses documentos estão: manuais pedagógicos, livros didáticos, revistas pedagógicas, legislações escolares, programas de ensino, cadernos escolares, provas, exames, avaliações, diversos materiais advindos de acervos pessoais, entre outros.
} 
O Projeto Temático conta com diversas pesquisas acadêmicas ${ }^{6}$ em âmbito nacional, que têm em comum o objetivo geral: "investigar os processos e dinâmicas de constituição do saber profissional do professor que ensina matemática no período compreendido entre 1890-1990" (VALENTE et al., 2017, p. 30) e que buscam responder às questões norteadoras dessa ampla investigação. São elas: "Como são produzidos, sistematizados e institucionalizados os saberes profissionais, os saberes profissionais do professor que ensina matemática? Como caracterizar a matemática como um saber profissional da docência?" (VALENTE et al., 2017, p. 10).

Para responder a essas interrogações, e caracterizar o saber profissional do professor que ensina matemática nesses cem anos, destacamse as pesquisas das autoras deste artigo, o doutorado concluído por Bruna Lima Ramos Giusti; e, o doutorado em andamento de Andréia Fernandes de Souza. Ambas objetivam caracterizar os saber profissional do professor que ensina matemática nos primeiros anos escolares.

Para analisar a constituição desses saberes, do modo proposto no Projeto Temático, elegeram-se, como ferramental teórico-metodológico: conceitos advindos da História Cultural, de estudos Sócio-Históricos e da História da Educação, bem como a História da educação matemática. Desse embasamento teórico destacam-se: processos (BURKE, 2016), saberes profissionais (HOFSTETTER; SCHENEUWLY, 2017) e, mais próximo deste objetivo teórico, os conceitos de matemática a ensinar e matemática para ensinar (BERTINI; MORAIS; VALENTE, 2017).

Neste sentido, para caracterizar uma matemática $a$ e para ensinar, a análise de documentos escolares é o marco inicial dessas pesquisas. A tese de Giusti (2020) apresenta a análise de alguns cadernos de normalistas de Prática, mais especificamente do ensino da rubrica de Metodologia da Aritmética, da década de 1950. A autora procura compreender o saber profissional que elas adquiriram durante o curso da escola normal e que poderia ser sistematizado para o utilizarem quando se tornassem professoras

\footnotetext{
${ }^{6}$ Entre iniciação científica, mestrado, doutorado e pós-doutorado.
} 
do curso primário. O artigo de Souza (2020), que contém resultados parciais da tese desta autora, analisa os artigos de revistas pedagógicas entre as décadas de 1890 e 1960 que abordavam o ensino de problemas aritméticos. O ponto de intersecção dos estudos realizados por ambas autoras é a constituição do saber profissional do professor que ensina matemática, particularmente os problemas de aritmética do curso primário, como pode ser visto num primeiro movimento de encontro em Souza e Giusti (2019).

Para este artigo, retoma-se o caderno escolar de Prática, de Thereza Pereira da Rocha, produzido no ano de 1958, durante um curso de aperfeiçoamento. Esse caderno foi alvo do estudo de Souza e Giusti (2019), quando as autoras tencionaram não apenas relacionar o ensino de problemas nele registrados, com as orientações de programas de ensino e revistas pedagógicas das décadas de 1940 e 1950, como também encontrar elementos que caracterizassem a matemática a ensinar e a matemática para ensinar os problemas aritméticos. Ou seja, buscaramse nele elementos presentes possíveis de notabilizarem os saberes profissionais para o ensino de problemas, postos na década de 1950.

Para cumprir tais objetivos - caracterizar esses saberes profissionais -, o estudo apoia-se na metodologia de pesquisa, conceituada por Peter Burke (2016, p. 74, grifos nossos), que afirma que a pesquisa historiográfica pode ser dividida em “[...]quatro estágios principais da sequência da obtenção ao uso da informação: coleta, análise, disseminação e utilização [...]". Essas etapas, descritas por Peter Burke (2016), se constituem em passos metodológicos, muitas vezes difíceis de serem inseridos em pesquisas qualitativas. Por conta disso, inicialmente Valente (2018) e, em seguida, Lima e Valente (2019), se apropriaram dessas fases e as trouxeram para a História da educação matemática, propondo procedimentos metodológicos que melhor se encaixam às pesquisas que tratam do saber profissional.

Assim, com o objetivo de caracterizar os processos e as dinâmicas de construção do saber profissional, Valente (2018) indica as seguintes 
etapas de trabalho: recompilação de experiências docentes, análise comparativa dos conhecimentos docentes, sistematização e análise do uso dos conhecimentos como saberes (VALENTE, 2018).

A recompilação de experiências docentes é quando o pesquisador fará “seleção e separação de informações" em documentos, a fim de "evidenciar informações sobre o trabalho pedagógico dos professores" (LIMA; VALENTE, 2019, p. 940), e de o reunir "conhecimentos dispersos num dado tempo histórico” (2019, p. 940).

A análise comparativa dos conhecimentos docentes é quando o pesquisador poderá fazer uma nova seleção a partir do que foi feito anteriormente. Esse novo inventário pode indicar tendências sobre as experiências docentes em um certo tempo, o que permitirá a construção de consensos pedagógicos sobre o ofício do professor (LIMA; VALENTE, 2019, p. 941).

Por fim, a sistematização e análise do uso dos conhecimentos como saberes é quando o pesquisador reunirá todos esses conhecimentos utilizados pelos professores, que podem ser generalizados, ou seja, passíveis de serem sistematizados em determinada época, e caracterizá-los como saber profissional do professor que ensina matemática. Conforme Lima e Valente (2019, p. 941), esta etapa também inclui a "verificação em instâncias normativas e/ou didático-pedagógicas da ocorrência de uso dos elementos sistematizados pelo pesquisador”.

De todo modo, o uso dessas três etapas ou procedimentos auxilará caracterizar o saber profissional do professor que ensina matemática, o qual se estabelece a partir da relação entre a matemática a e para ensinar.

Essa metodologia de análise já tem sido empregada em algumas pesquisas concluídas do GHEMAT7, como, na análise dos cadernos de normalistas feita por Giusti (2020), incluindo o caderno de Rocha (1958). A partir dessas pesquisas foi possível sistematizar, caracterizar e discutir o saber profissional do professor que ensina matemática nos primeiros anos

\footnotetext{
${ }^{7}$ Como se pode ver nos trabalhos de Maciel (2019) e Giusti (2020).
} 
escolares. Para este artigo, o olhar estará voltado para o ensino de problemas, presente nesse caderno da década de 1950, com base em autores do final do século XIX e do século XX.

\section{De Pestalozzi a Thorndike: breve histórico}

O ensino, por muito tempo, foi marcado por algumas características definidas, tais como: elitização dos conteúdos, enciclopedismo, memorização, catequético, desencadeamento das ideias por meio da organização da própria disciplina, entre outros. Essas características advêm de um modelo, dito e reconhecido, como sendo tradicional (SAVIANI, 2011).

Nessa toada, o ensino tinha a aparência daqueles moldes utilizados na catequização dos indígenas, que consistia em, a partir de perguntas e respostas, conseguir ensinar e aprender os princípios cristãos. Essas características permanecem e coexistem com outras até os dias atuais.

Em dado momento, o Estado tomou para si a responsabilidade de oferecer a educação como um direito, e a sociedade começou a vislumbrar a educação como forma de ascensão social e melhoria das condições de vida. Concomitantemente foi surgindo um movimento de mudança nos moldes de ensinar.

Em meados do século XIX, observa-se mundialmente a necessidade da criação de um novo método de ensino, que pudesse superar a pedagogia tradicional, como pontua Valente (2008, p.1):

\footnotetext{
Buscou-se um novo método de ensino. Ele viria acompanhado de novos materiais, criação de Museus Pedagógicos, excursões pedagógicas dentre outras atividades. Esse novo método ganhou vitrine nas Exposições Universais, organizadas para a difusão de práticas pedagógicas renovadas, materiais didáticos e suas aplicações. $O$ novo método caracterizou-se pela proposta de um ensino concreto, ativo, a ser denominado de ensino intuitivo.
} 
O método intuitivo, tendo como o seu maior divulgador o educador suíço Johann Heinrich Pestalozzi (1746-1827), parecia uma alternativa e uma grande aposta para a melhoria do ensino.

Esse método tinha como principal fundamento a valorização da intuição, privilegiando os sentidos, a observação para a aquisição do conhecimento, a experimentação, o concreto, opondo-se ao ensino dito tradicional.

O assim chamado "método intuitivo" deve essa denominação à acentuada importância que os seus defensores davam à intuição, à observação, enquanto momento primeiro e insubstituível da aprendizagem humana. [...] os defensores do método intuitivo chamaram a atenção para a importância da observação das coisas, dos objetos, da natureza, dos fenômenos e para a necessidade da educação dos sentidos como momentos fundamentais do processo de instrução escolar. (FARIA FILHO, 2003, p. 143, grifo do autor)

Para Pestalozzi, a intuição não era meramente uma observação passiva de objetos, mas incluía também a atividade intelectual, com perguntas que levassem ao desenvolvimento integral das crianças.

Soetard (2010, p. 89) afirma que "toda filosofia leva consigo uma pedagogia; e o inverso, toda pedagogia supõe uma filosofia”. Com essa frase, ele justifica que a pedagogia proposta por Pestalozzi tinha grande relação com o pensamento de Immanuel Kant ${ }^{8}$.

Visto que o método intuitivo apresentava como seus pressupostos os aforismos de Pestalozzi, que priorizam a aprendizagem, partindo "do concreto para o abstrato", "do fácil para o difícil”, "do conhecido ao desconhecido", "da percepção das coisas por meio do contato direto" (ZANATA, 2012, p. 107), a educação não poderia ser repressora e era o meio para que as capacidades cognitivas, as afetivas e o caráter fossem desenvolvidos.

Pestalozzi pensava a educação de modo amplo, e o método intuitivo poderia ser utilizado em todas as disciplinas e para todos os alunos. E por conta disso, suas ideias circularam no Brasil desde o final

\footnotetext{
${ }^{8}$ Immanuel Kant (1724-1804) é considerado o principal filósofo da era moderna que sintetizou o racionalismo e a tradição empírica inglesa (que se baseava na indução), conforme Soetard (2010).
} 
do século XIX, por meio dos programas de ensino, livros escolares, artigos de revistas pedagógicas e em cursos para formação de professores. Ele modificou preceitos da pedagogia tradicional, buscando olhar a criança e educá-la a partir dos sentidos.

Já Edward Lee Thorndike (1874-1949), norte-americano, nasceu após o término da Guerra Civil Americana em Massachusetts. Thorndike "graduou-se na Wesleyan University, em 1895; concluiu o mestrado em Harvard, em 1897; o doutorado na Columbia, em 1898" (RABELO, 2016, p. 49).

Em 1917, publicou o livro The Thorndike Arithmetics, mas há indícios de seu apreço pelo assunto em anos anteriores, conforme aponta Rabelo (2016, p. 74), "é possível retroceder pelo menos até 1909, quando publicou o livreto Exercises in arithmetic, selected, graded and arranged to meet the requirements of the hygiene of the eye and neuro-muscular apparatus". E o interesse de Thorndike por matemática continuou com o passar dos anos, publicando os livros New methods in arithmetic, em 1921, e, em 1922, Psychology of arithmetic.

Thorndike foi contratado como professor do Teachers College, na Columbia University, em 1899. Em 1920, dado seu reconhecimento pelas obras publicadas, foi convidado a auxiliar na implementação de políticas a respeito dos currículos escolares nos Estados Unidos. Suas ideias, advindas da psicologia experimental e conexionista ${ }^{9}$, vistas como uma nova psicologia, estavam voltadas ao ensino da língua materna e da matemática.

No Brasil, é possível perceber as apropriações e as circulações desse autor $^{10}$. Um dos indícios desse interesse por escritos de Thorndike se revela pela tradução da sua obra, publicada em 1936, A nova metodologia da aritmética, feita por Anadyr Coelho. Esse livro foi muito citado em artigos de revistas pedagógicas na época e aparecia como referência nos Programas de Ensino até meados da década de 1960.

\footnotetext{
9 Esses estudos tinham como base a relação estímulo-resposta, uso e desuso, reações a partir dos efeitos da aprendizagem (RABELO, 2016).

${ }^{10}$ Ver Rezende (2016).
} 
FIGURA 1: Folha de rosto do livro A nova metodologia da Aritmética, do autor americano Edward Lee Thorndike

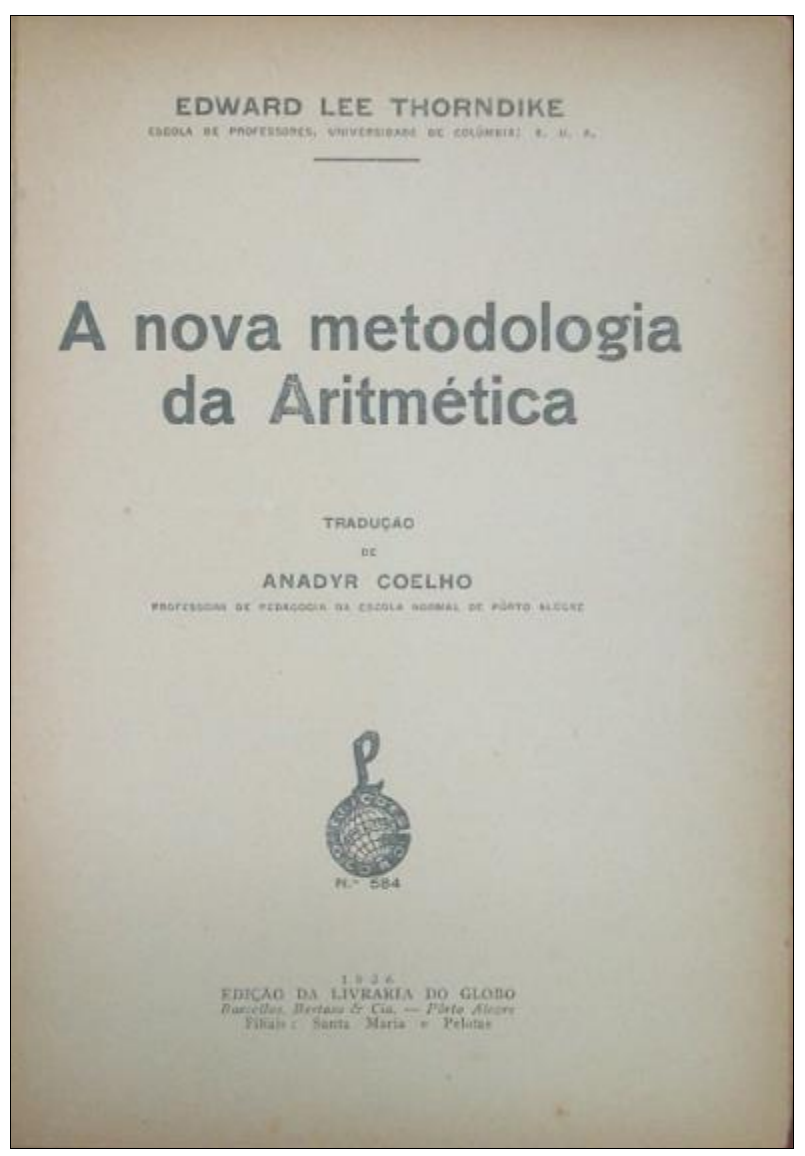

Fonte: Thorndike (1936). Disponível em: https://repositorio.ufsc.br/handle/123456789/134890.

Thorndike apresenta diversas falas interessantes neste livro e parece estranho o fato de, a todo momento, mostrar ao leitor duas facetas dos métodos escolares: o velho e o novo.

Suas críticas são em torno de velhos métodos empregados para o ensino de aritmética. Tece, ainda,comentários acerca do ensino da língua materna, fazendo alusão ao método sintético no qual se aprendem as letras, depois sílabas, palavras, frases e textos, indicando essa mesma lógica para a aritmética. Critica as repetições e os enfadonhos exercícios, como se vê:

A Lei do Exercício, assim enunciada: o uso fortifica e o desuso enfraquece as conexões mentais. E a Lei do Efeito, assim enunciada: As conexões acompanhadas ou seguidas de 
estados de satisfação tendem a fortalecer-se; as conexões acompanhadas ou seguidas de estados de aborrecimento, tendem a enfraquecer-se. (THORNDIKE, 1936, p. 78)

Diferentemente de Pestalozzi, Thorndike se apropriou de um referencial, o da psicologia conexionista, e construiu uma forma de ensinar aritmética. Dito de outro modo, ele elaborou um saber para ensinar aritmética, que seria usado nas escolas durante um período do século XX.

Tendo como parâmetro, registros feitos em um caderno, produzido em uma escola normal, pode-se afirmar que Pestalozzi, nascido no século XVIII, e Thorndike, nascido no século XIX, conviveriam juntos, nos escritos de Thereza Pereira Rocha no século XX.

\section{Escritos de Thereza Pereira Rocha: Caderno de Prática, Metodologia da Aritmética, São Paulo, 1958}

O Caderno, de Thereza Pereira Rocha (1958)11 foi produzido em um curso de Aperfeiçoamento, realizado em São Paulo. Ela era uma professora normalista do curso primário, e esse curso de aperfeiçoamento era específico para a formação do professor. O caderno analisado é da disciplina de Prática, ou seja, possui registros de diversas matérias, e dentre elas, há a "Metodologia da Aritmética". Ao final desse caderno, é possível ver uma parte destinada a um diário de classe, provavelmente utilizado em sala de aula com alunos do curso primário.

Por se tratar de um caderno de Prática, nele se pode perceber a forma como a normalista pretendia ensinar alguns conteúdos da aritmética, entre os quais: unidade, dezena, centena, as quatros operações (soma, subtração, multiplicação e divisão), metragem, frações e problemas. Além disto, também é possível verificar algumas considerações em relação ao método a ser utilizado, bem como indicações

11 Esse caderno está digitalizado no Repositório de Conteúdo Digital e pode ser acessado por meio do link: https://repositorio.ufsc.br/handle/123456789/163509. 
de manuais pedagógicos e programas de ensino. Ao que tudo indica, esse caderno foi construído com base nas instruções postas pela época.

Ao longo desse caderno, têm-se diversas ilustrações coloridas, desenhadas de lápis de cor ou colagens.

FIGURA 2: Desenhos representando quantidade para abtração aritmética

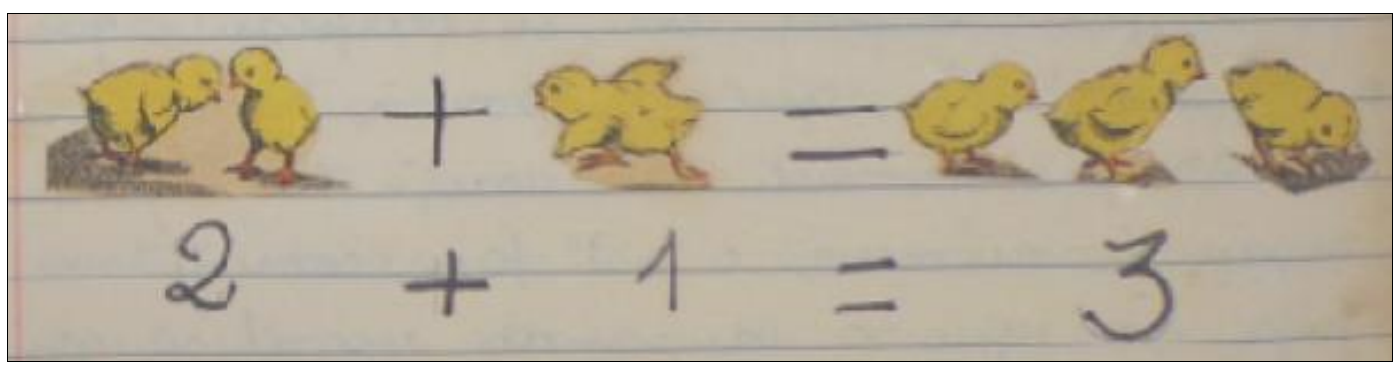

Fonte: Rocha (1958, p. 8)

A normalista afirma que utilizar ilustrações serve para que a criança relacione as quantidades com os algarismos correspondentes. Isto seria um processo de iniciação da abstração aritmética. Segundo Rocha (1958), o método utilizado anteriormente, desde a década de 1920, para ensinar aritmética às crianças era o dedutivo.

Nos tempos primitivos, julgava-se que o ensino da aritmética tinha que ser exclusivamente dedutivo. Baseado nessa concepção, é que, até a bem pouco tempo, a subtração se processava do seguinte modo:

$$
\text { Ex: }-\frac{123}{25}
$$

Esta operação se realizava do seguinte modo: de 3 não se pode tirar 8 , o 3 empresta 1 do 2 , que vale 10 , e assim o 3 passa a valer 13; de 13 tira $8=5$. O 2 passa a valer 1 . Não pode tirar 9, empresta 1 da casa seguinte, que vale 10 , e assim o 1 passa a valer 11 . De 11 tira $9=2$. O 1 vale zero, e o cálculo está concluído (dedução). (ROCHA, 1958, p. 4-5)

Com isso, Rocha (1958) aponta que esse método vinha sendo substituído pelo método indutivo. Segundo Maciel (2019), o método indutivo consistia em memorizar por meio da repetição. Foi muito 
utilizado até o final do século XIX, pelo fato de que os professores tinham dificuldade de trocar esse método pelo "novo método", isto é, pelo método intuitivo. Ou seja, Rocha (1958) critica esse método de repetição, que parece ter permanecido por muito tempo no ensino da aritmética.

No caderno de Rocha (1958), a normalista menciona uma obra de Thorndike, $A$ metodologia da aritmética, e afirma, com base nessa obra, que a criança precisa "contar coisas, tais como: bolinhas, pedrinhas, etc" (1958, p. 5), isso seria um apelo desse autor para a "observação da realidade".

Ainda baseada nos preceitos de Thorndike, a autora pontua que "os métodos antigos apresentavam uma grande falha. Ensinavam a aritmética pela aritmética, sem consideração para com as realidades da vida" (1958, p. 5). Isto porque os métodos anteriores apresentavam "contas quilométricas e sutilezas inúteis" (ibidem).

Os problemas aritméticos aparecem ao longo desse caderno. A normalista registra que o método indutivo recomendava o uso de "problemas reais, cálculos que constantemente apareciam na vida cotidiana" (ROCHA, 1958, p. 5), pois no método anterior, o dedutivo, os problemas considerados satisfatórios eram os seguintes:

1) Alice tinha $3 / 8$ de um mil réis, Berta $14 / 16$, Maria $3 / 25 \mathrm{e}$ Nena $3 / 4$. Quanto possuíam juntas?

"Só num hospício, um problema com estas características poderia aparecer" (Thorndike).

2) Um homem tem a altura $1,80 \mathrm{~m}$, e pesa $83 \mathrm{kgs}$. Qual será a altura de sua esposa, sabendo-se que seu peso é de $62 \mathrm{kgs}$ e sua estatuta é proporcional a do marido?

Diz o autor: "Êste problema é fútil e extravagante". (Rocha, 1958, p. 6)

O autor, ao qual a normalista se refere, é Thorndike. Sobre os problemas, Rocha (1958) afirma que, mesmo na década de 1950, ainda havia esses tipos de problemas reais: "Gastei 2/3 do dinheiro que possuía e mais $1 / 5$ do resto. Quanto eu tinha, sabendo-se que ainda voltei pra casa com $x$ ?" (1958, p. 6). A normalista aponta que, apesar de ser um tipo de problema real, é pouco provável de ocorrer na vida de fato. A 
autora explica que Thorndike diz que os novos métodos pedem por um ensino "em absoluta harmonia com a situação real da vida" (ibidem).

Por isso, segundo Rocha (1958), que Thorndike indica que um item importante na metodologia da aritmética é o interesse. O professor deve despertá-lo nas crianças, por isso não era recomendado o uso de problemas muito extensos para copiarem, pois, dessa forma, elas poderiam perder o interesse no momento de os calcular.

A sugestão seria utilizar "cadernos graduados”, ou então, o papel mimeografado. Esses recursos serviriam para economizar a energia das crianças, para que elas a utilizassem na solução dos cálculos. Rocha (1958, p. 7) reitera que é preciso “compreensão, e não simples repetição". Ao que parece, a normalista procura enfatizar que a criança deve compreender o problema e, para isso, cabe utilizar o interesse delas para envolvê-las no ensino de aritmética.

A autora fala, a partir de Thorndike, que a iniciação aritmética deve ser feita em três fases: "A primeira consiste na apresentação da realidade, a $2^{\mathrm{a}}$, na apresentação de desenho correspondentes à realidade, e finalmente a apresentação de símbolos ou sinais gráficas, correspondentes à realidade" (ROCHA, 1958, p. 7).

Ou seja, primeiro seria mostrar para as crianças os objetos reais, por exemplo, uma laranja. Em seguida, o desenho de uma laranja. E só depois apresentar os algarismos, para que elas os relacionassem com os objetos estudados, pois, apenas apresentando a forma abstrata (os algarismos), as crianças não compreenderiam o significado do porquê $2+$ 2 ser igual a 4 . 
FIGURA 3: Adição explicada de forma concreta

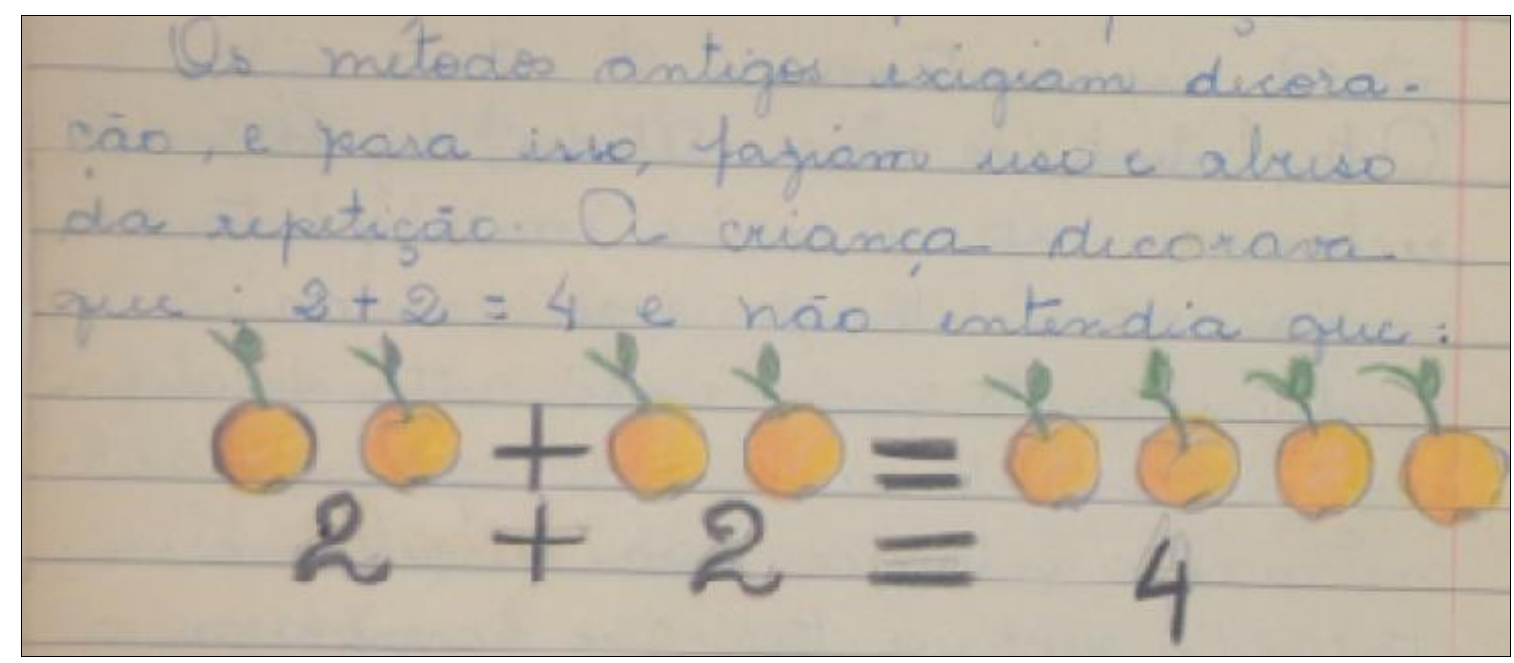

Fonte: Rocha (1958, p. 7)

Por meio da Figura 3, é possível perceber que a criança poderá compreender pela forma visual que duas laranjas mais duas laranjas serão quatro laranjas. Ao que tudo indica, a normalista é a favor da observação, com objetos, para depois ensinar os algarismos, assim como Thorndike recomendava.

Para essa normalista, o ensino deve partir do concreto para o abstrato. Um exemplo disso seria mostrar ilustrações de laranjas e somá-las. Sendo assim, a criança conseguiria visualizar a quantidade e somar até chegar ao resultado de laranjas no final. Um problema mais abstrato seria perguntar à criança quantos irmãos ela tem, pois assim teria que imaginar a quantidade e falar o número.

Ela indica que esses tipos de problemas poderiam ser feitos oralmente, ou utilizar desenhos feitos na lousa ou nos cartazes, como um recurso didático. Então, inicialmente os alunos veriam a imagem e deveriam dizer a palavra "três". Mas com o passar do tempo, eles aprenderiam a escrever e relacionar essa palavra com a forma gráfica " 3 ". A normalista enfatiza que a criança precisa compreender o que o problema está pedindo e não o resolver simplesmente por mera repetição.

Neste mesmo caderno, a autora, no entanto, também defende a utilização das concepções de Pestalozzi. Para a iniciação matemática, esse 
autor aponta três fases distintas: primeiro verificar o que a criança sabe, assim que entra na escola; depois, dar a ela a noção de número; e por último, fazê-la reconhecer grupo de coisas e objetos (ROCHA, 1958, p. 9). Entendese, por essa orientação, que somente depois dessas três noções elementares é que se deveria iniciar o ensino das quatro operações fundamentais.

Para o ensino da representação gráfica, a autora afirma que Pestalozzi recomenda a forma associada, ou seja, "associa-se a representação gráfica ao desenho correspondente” (ROCHA, 1958, p. 10). Inicialmente, a normalista sugere o uso de desenhos de bolinhas, "por ser mais fácil para a criança copiar" (1958, p. 10), para depois fazer desenhos de objetos mais "animados" para as crianças, como borboletas, passarinhos, peixes etc.

FIGURA 4: Exemplo de gráfico de Pestalozzi no caderno de Rocha (1958)

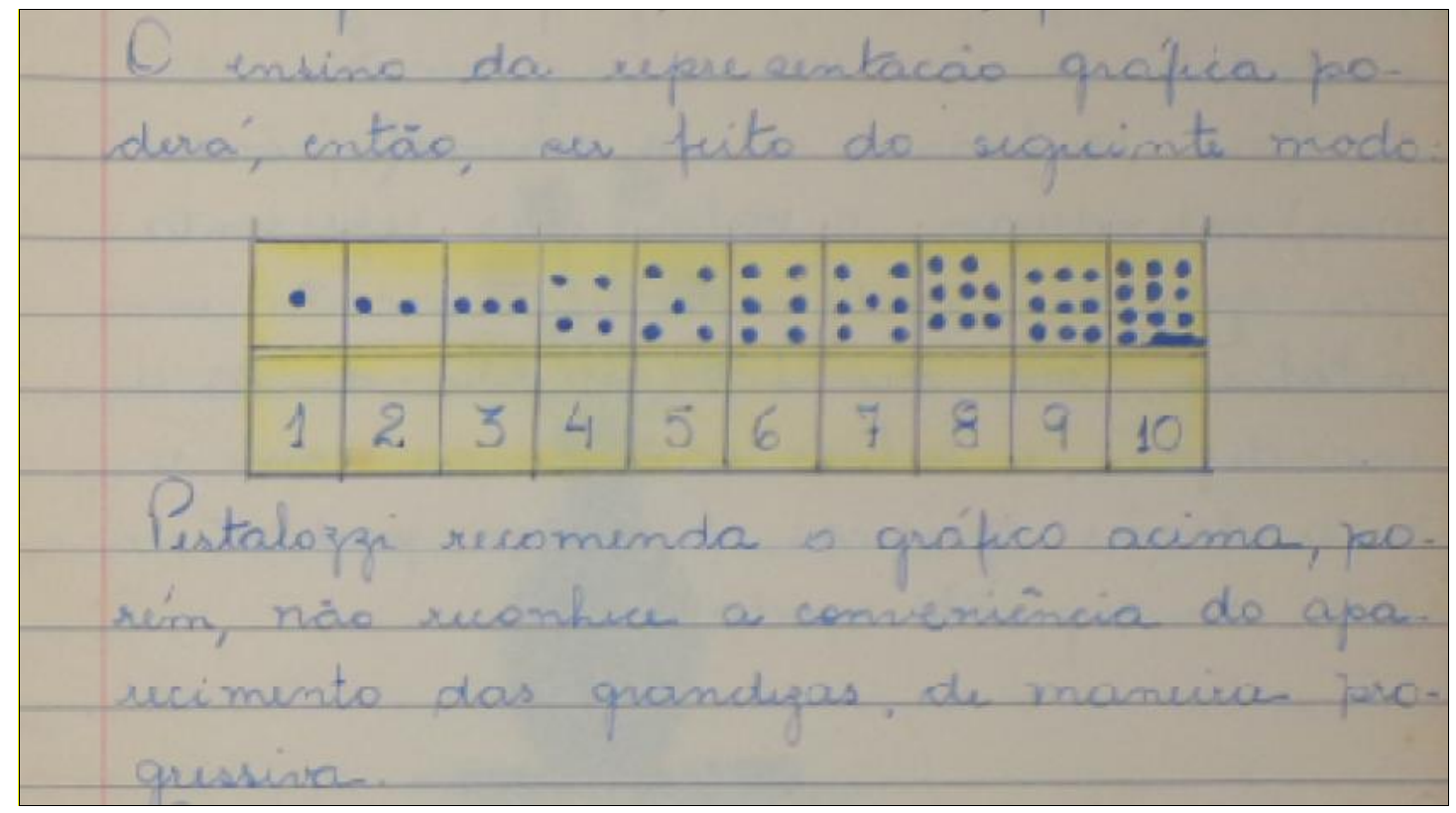

Fonte: Rocha (1958, p. 10)

Para que as crianças dominem a representação gráfica dos números, Pestalozzi recomenda outros passos, conforme a autora registra: "1. Observação atenta ao gráfico que representa ao mesmo tempo, a grandeza e sua respectiva representação gráfica” (ROCHA, 1958, p. 10), ou seja, ao 
gráfico apresentado na Figura 3, que contém as quantidades e os algarismos. "2. Apagar levemente os sinais que representam as grandezas, a fim de que os sinais gráficos correspondentes impressionem melhor o sentido da visão" (1958, p. 10) e "3. Apagar completamente as grandezas, e exigir a repetição da leitura e da cópia das representações gráficas já estudadas" (1958, p. 11). Entende-se que isso seria ir apagando aos poucos os desenhos até deixar somente os algarismos.

A normalista Rocha (1958) indica, no caderno, que a recomendação dada na época era que o ensino das quatro operações aparecesse de forma concomitante. Ao que tudo indica, essa seria a primeira fase, a partir de objetos concretos. Depois, seria possível seguir para os desenhos, em que a criança vê relação entre o objeto e um desenho desse objeto, como pode ser observado na Figura 5.

FIGURA 5: Processos para ensinar adição e subtração a partir do concreto

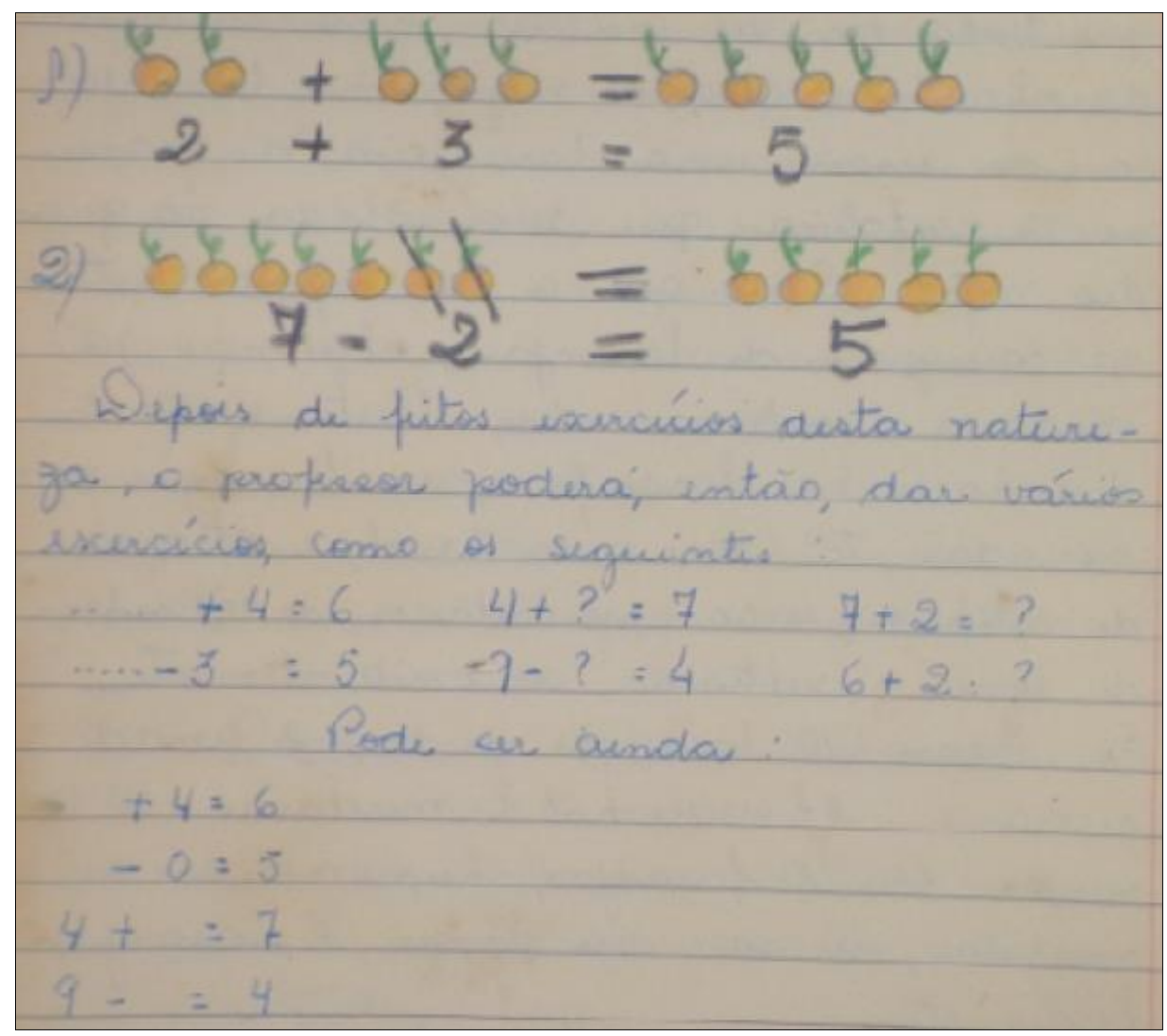

Fonte: Rocha (1958, p. 14) 
A Figura 5 mostra que a normalista entende que o ensino dos algarismos, a partir de desenhos, seria uma forma de a criança compreendê-los. Depois desta fase, o professor poderia passar exercícios apenas com números, somando ou subtraindo, fosse para encontrar o resultado final ou um dos números da conta.

No caderno de Rocha (1958), é apontado que um dos conteúdos do ensino primário seria o dos problemas. Para a resolução ou a exemplificação de alguns desses, a normalista utiliza objetos ou ilustrações. Para introduzilos às crianças, precisaria primeiro passar a fase da iniciação aritmética, que consistia em mostrar o objeto, depois o desenho desse objeto e, só, então, relacionar a quantidade com os números.

Segundo a normalista, "as noções da divisão devem ser apresentadas antes das noções de multiplicação. A criança entende com mais facilidade a divisão do que a multiplicação" (1958, p. 16). Ela propõe um exercício para introduzir a noção de divisão, como um primeiro passo. A atividade consiste na professora segurar oito lápis em suas mãos e perguntar às crianças "qual a metade de 8?", e depois de "vários artifícios", as crianças poderiam responder que a metade de oito é igual a quatro.

Uma outra atividade que a normalista sugere para o professor ensinar a noção da multiplicação seria o professor desenhar três árvores, cada uma com três frutos. E, com base nesse desenho, ele poderia fazer as perguntas. Talvez as crianças contassem a quantidade de frutos, mas isso faria com que elas compreendessem o sentido da multiplicação e, em seguida, da tabuada.

Neste caderno, após apresentar todos os conteúdos de aritmética que devem ser dados às crianças, a normalista faz uma comparação do primeiro e do último exercício que um livro didático, intitulado Raciocine com a criança, de Claedmar French, propõe para cada ano de ensino, apresentado no Quadro 1. 
QUADRO 1: Sugestão de exercícios e problemas seriados

\begin{tabular}{|c|c|c|}
\hline & Primeiro exercício & Último exercício \\
\hline $1 .^{\circ}$ ano & $\begin{array}{l}\text { Desenhar bolinhas para as crianças } \\
\text { identificarem os algarismos } \\
\text { correspondentes (até o número 5). }\end{array}$ & $\begin{array}{l}\text { Problema: "Uma peça de renda } \\
\text { mede } 27 \text { metros. Quanto medem } 3 \\
\text { peças iguais?" }\end{array}$ \\
\hline $2 .^{\circ}$ ano & $\begin{array}{l}\text { Ensino da unidade, dezena, centena e } \\
\text { milhar, por meio de um quadro. }\end{array}$ & $\begin{array}{l}\text { Problema: "De um cesto com } 2 \\
\text { centenas de laranjas, tirei a } 5 .^{\text {a }} \\
\text { parte para distribuir entre } 8 \\
\text { crianças. Quantas laranjas } \\
\text { recebeu cada criança?" }\end{array}$ \\
\hline $3 .^{\circ}$ ano & $\begin{array}{l}\text { Problema: "Quanto custam } 43 \\
\text { peras a } \operatorname{Cr} \$ 1,60 \text { cada uma?" }\end{array}$ & $\begin{array}{l}\text { Problema: “Os } \frac{2}{8} \text { de } \mathrm{Cr} \$ 298,50 \text { é o } \\
\text { preço de um metro de seda. } \\
\text { Quanto pagarei por } 3,40 \mathrm{~m} ? "\end{array}$ \\
\hline $4 .^{\circ}$ ano & $\begin{array}{l}\text { Problema: “A diferença de preço } \\
\text { entre } 2 \text { objetos é de } \operatorname{Cr} \$ 149,00 \text {. } \\
\text { Sabendo-se que o mais caro custou } \\
\text { Cr } \$ 324,00 \text {, qual é o preço do outro?" }\end{array}$ & $\begin{array}{l}\text { Problema: "Comprei uma carteira } \\
\text { por Cr } \$ 180,00 \text { e a vendi por } \\
\text { Cr } \$ 130,00 . \text { Qual a porcentagem } \\
\text { de prejuízo?" }\end{array}$ \\
\hline
\end{tabular}

Fonte: produzido pelas autoras a partir de Rocha (1958, p. 21-22)

Para o $1 .^{\circ}$ ano, a normalista afirma que prefere trabalhar com laranjas, em vez de bolinhas com as crianças. Porém, para os demais exercícios e problemas, ela não faz nenhum comentário sobre a indicação que o livro didático Raciocine com a criança propôs, apesar de ela criticar problemas que não sejam reais e defender que eles sejam do interesse da criança. Esses problemas, apresentados no Quadro 1, a partir desse livro didático, parecem se aproximar da vida real, mas não se sabe se estão de acordo com o interesse das crianças.

Esses conteúdos matemáticos, apontados por Rocha (1958), surgem como objeto de ensino, que, segundo Valente et al. (2017) podem ser chamados de uma matemática $a$ ensinar.

Rocha (1958) também sugere que o professor utilize outros documentos para preparar suas aulas do curso primário, como Começando a calcular, de Lília N. P. Visani; Nossa vendinha; o Programa Escolar; o Manual do ensino primário, de Miguel Milano; entre outros. 


\section{De Pestalozzi à Thorndike, saberes para ensinar problemas aritméticos}

Observa-se que, no caderno de Rocha (1958), os autores Pestalozzi e Thorndike transitam, subsidiando os saberes profissionais. Pestalozzi sistematizou uma ferramenta de trabalho docente, o método intuitivo, embasado nos sentidos e no olhar mais sensível com aqueles que estão aprendendo. Thorndike, do mesmo modo, elaborou uma ferramenta, a partir das pesquisas relacionadas à psicologia conexionista, uma matemática para ensinar, levando em conta aspectos como o interesse infantil. E tais ferramentas se fazem presentes nos registros de Rocha (1958) e denotam a construção de um saber profissional do professor que ensina matemática nos anos iniciais.

A utilização das ilustrações nas aulas demonstra a preocupação com o entendimento da criança, visto que os números e as quantidades são questões abstratas para ela, no início da aprendizagem, bem como as definições sobre números e algarismos que estavam presentes em livros de aritmética, em tempos de pedagogia tradicional.

A ideia era a de que fosse respeitada a gradação do desenvolvimento do aluno e não o desenvolvimento da disciplina. A matemática era apresentada no ensino tradicional, com definição, regras, exemplos e exercícios. Portanto, pensar em objetos concretos para caminhar até a construção do conceito de número seria transitar do fácil para o difícil.

Neste cenário, lançar mão de recursos tais como ilustrações, objetos concretos, mapas de Parker ${ }^{12}$, ter uma sequência para ensinar as operações fundamentais, graduar o ensino, eram vistas como inovações no período. Em Rocha (1958), é possível verificar que a normalista indica o uso de alguns recursos didáticos, entre eles estão os próprios mapas de Parker.

\footnotetext{
${ }^{12}$ Cartazes sequenciados com o objetivo de ensinar os algarismos e as operações. Ver Valente (2008).
} 
Essa graduação, como mostra o caderno de Rocha (1958), pode ser percebida quando ela tem um modelo de problema aritmético para o início e para o final do ano letivo, conforme exemplo ilustrado no Quadro 1.

Thorndike (1936) trazia análises minuciosas das operações fundamentais, mas defendia que, mesmo os alunos que sabiam realizar cálculos, poderiam não conseguir resolver problemas. Esse autor defendia, ao longo do seu livro, o interesse e a motivação como meios de aguçar a curiosidade das crianças em aprender. Para tal feito, os problemas seriam excelentes propostas, desde que seguissem as seguintes recomendações:

Todo problema deve, de preferência, (1) versar sobre situações que apresentem toda a probabilidade de ocorrer muitas vezes na vida real; (2) trata-las do modo por que o seriam na vida prática; (3) apresenta-las sob uma feição nem muito mais difícil, nem muito fácil. (THORNDIKE, 1936, p. 153)

Rocha (1958) também apresenta forte influência desse autor, pois ela se preocupa com o interesse da criança. Com essa tríade, Thorndike (1936) propunha situações possíveis tanto de acontecer quanto de serem resolvidas por cada criança.

Registra também que o professor precisaria observar três elementos na solução de um problema: “(1) a compreensão exata da questão, (2) o conhecimento dos fatos que se devem utilizar para solucioná-la, (3) o uso dêsses fatos em corretas relações aritméticas" (THORNDIKE, 1936, p. 154).

Outro destaque dado pelo autor é o de que nem todo problema, só pelo fato de carregar em seu enunciado palavras do cotidiano infantil, despertariam o interesse. Era necessário mobilizar outras formas. No caderno da normalista, se percebe a mesma crítica quanto aos problemas do cotidiano, pois alguns deles não fariam muito sentido às crianças. Apesar de ela concordar com isso, ainda aparecem alguns problemas desse tipo em seu caderno: reais, porém difíceis de acontecer.

Thorndike, tendo uma base na psicologia conexionista, defendia em seu livro que os problemas eram excelentes testes de inteligência e 
serviriam para "informar o professor da capacidade absoluta de cada aluno", "informar o aluno de sua capacidade absoluta" e "para estimular o professor auxiliar a classe e melhorar a qualidade dos trabalhos" (THORNDIKE, 1936, p. 279). Os problemas eram meios de testar os alunos.

Enfim, assim como Giusti (2020) destacou, é possível perceber que essa miscelânea de orientações trazida pelos manuais pedagógicos fazem com que esses manuais ganhem status de uma matemática para ensinar (VALENTE et al., 2017). Essa matemática para ensinar pode ser vista como uma ferramenta para o professor do curso primário, conforme afirmaram Hofstetter e Schnewly (2017).

\section{Conclusão}

Como se pode observar, o caderno de Rocha (1958) possui inúmeras referências tanto a Pestalozzi, que preconizou o método intuitivo no final do século XIX, como a Thorndike, representante da psicologia conexionista, do início do século XX. Apesar de a normalista sempre se referir aos métodos anteriores como "ultrapassados", ela se baseia em métodos construídos e pensados por autores do método intuitivo e da escola nova. Cabe ressaltar que a década de 1950 ficou marcada por mudanças no ensino escolar, conforme Giusti (2020) e, em meados dos anos de 1960, começaram os indícios de um novo método para o ensino da matemática: o Movimento da Matemática Moderna.

Sendo assim, o que se percebe é que apesar de a normalista criticar os métodos anteriores, na verdade os métodos modernos apenas vieram aprimorar aqueles que foram disseminados num tempo anterior. Pestalozzi usava a intuição para a observação, os sentidos como forma de aprender. Thorndike afirmava que com a observação a criança adquiriria a abstração e que as aulas tinham que levar em conta o interesse da criança e sua vida prática. 
Contudo, quando Rocha (1958) sugere alguns problemas que estavam em um livro didático sem questioná-los, nota-se que nem sempre o ensino de problemas seria relacionado ao interesse da criança ou que seria possível partir do concreto para o abstrato.

Cumpre ressaltar que Rocha (1958) estava iniciando suas práticas no curso primário, a partir de ferramentais adquiridos na escola normal. É possível que, naquele momento, o curso realizado por ela não tivesse fornecido maior aprofundamento a respeito de teorias sobre o desenvolvimento infantil e as ideias que Pestalozzi e Thorndike preconizavam, o que colaboraria para uma visão homogênea sobre o ensino de aritmética.

Entende-se que a relação estabelecida pela matemática $a$ ensinar e para ensinar, destacada no artigo, se mostra como saber profissional da docência.

Esses indícios levam à hipótese de que nesse curso de aperfeiçoamento, e possivelmente em outros de formação de professor, não se levava em conta se um autor era contrário às idéias do outro, ou se faziam parte de correntes opostas de pensamento. Ao que tudo indica, para a formação dos professores da década de 1950, eram selecionados de cada autor aquilo que se mostrava mais interessante e possível de ser aplicado no cotidiano escolar. Em suma, é possível perceber indícios de um saber profissional do professor que vai ensinar matemática no curso primário.

\section{Referências}

BERTINI, L. F.; MORAIS, R. S.; VALENTE, W. R. A matemática a ensinar e a matemática para ensinar - novos estudos sobre a formação de professores. 1. ed. São Paulo: L F Editorial, 2017. v. 1. 80p.

BURKE, P. O que é história do conhecimento? 1. ed. Tradução de Claudia Freire. São Paulo: Editora Unesp, 2016.

FARIA FILHO, L. M. Instrução elementar no século XIX. In: LOPES, E. M. T.; FARIA FILHO, L. M.; VEIGA, C. G. (orgs.). 500 anos de educação no Brasil. 3.ed. Belo Horizonte: Autêntica, 2003. p.135-204. 
GIUSTI, B. L. R. Cadernos de normalistas e a sistematização do saber profissional para ensinar aritmética no curso primário, década de 1950. 2020. Tese (Doutorado em Ciências) - Universidade Federal de São Paulo, Escola de Filosofia, Letras e Ciências Humanas, Programa de Pós-Graduação em Educação e Saúde na Infância e na Adolescência. Guarulhos. 2020.

GIUSTI, B. L. R; GODOI, A. J.; COSTA, D. A. Cadernos Escolares como Patrimônio da Educação Brasileira. ACERVO - Boletim do Centro de Documentação do GHEMAT-SP, v. 2, n. 2, p. 315-333, 2020.

HOFSTETTER, R.; SCHNEWLY, B. Saberes: um tema central para as profissões do ensino e da formação. In: HOFSTETTER, R.; VALENTE, W. R. (org.). Saberes em (trans)formação: tema central da formação de professores. São Paulo: Editora Livraria da Física, 2017. p. 113-172.

LIMA, E. B.; VALENTE, W. R. O saber profissional do professor que ensina matemática: considerações teórico-metodológicas. Argumentos Pró-Educação, v. 4, n. 11, 25 jun. 2019. DOI: https://doi.org/10.24280/ape.v4i11.500.

MACIEL, V. B. Elementos do saber profissional do professor que ensina matemática: uma aritmética para ensinar nos manuais pedagógicos (1880 1920). 2019. 312 f. Tese (Doutorado em Ciências) - Universidade Federal de São Paulo, Escola de Filosofia, Letras e Ciências Humanas, Programa de Pós-Graduação em Educação e Saúde na Infância e na Adolescência.

Guarulhos, 2019.

RABELO, R. S. Destino e Trajetos: Edward Lee Thorndike e John Dewey na formação matemática do professor primário no Brasil (1920-1960). Tese (Doutorado) - Faculdade de Educação da Universidade de São Paulo, São Paulo, 2016.

REZENDE, A. M. S. Apropriações de teorias de Edward lee Thorndike para o ensino dos saberes elementares matemáticos em revistas pedagógicas brasileiras.

Dissertação (Mestrado). Universidade Federal de Sergipe. São Cristovão, 2016.

ROCHA, T. P. Caderno de Prática: Metodologia da Aritmética. Curso de Aperfeiçoamento. São Paulo, 1958. Parte 1. (Manuscrito). Disponível em: https://repositorio.ufsc.br/xmlui/handle/123456789/163509. Acesso em: 05 mai. 2020.

SAVIANI, D. História das ideias pedagógicas no Brasil. 3. ed. Campinas, SP: Autores Associados, 2011.

SOETARD, M. Johann Pestalozzi. Recife: Fundação Joaquim Nabuco, Editora Massangana, 2010.

SOUZA, A. F. "Problema dos problemas": possíveis percursos de uma sistematização dos saberes profissionais (São Paulo, 1961). ACERVO - Boletim do Centro de Documentação do GHEMAT-SP, v. 2, n. 2, p. 205-220, 2020. 
SOUZA, A. F; GIUSTI, B. L. R. Documentos escolares com problemas: uma análise dos saberes profissionais (São Paulo, 1940-1950). In:CONGRESSO IBEROAMERICANO DE HISTORIA DE LA EDUCACIÓN MATEMÁTICA, 5., 2019. Bogotá. Anais [...].Bogotá: Universidad Distrital Francisco José de Caldas. 2019. p. 418-429. Disponível em: https://comunidad.udistrital.edu.co/cihem/memorias/. Acesso em: 10 jul. 2020.

THORNDIKE, E. L. A nova metodologia da Aritmética. Trad. Anadyr Coelho, Porto Alegre: Editora Livraria do Globo, 1936. Disponível em: https://repositorio.ufsc.br/handle/123456789/134890. Acesso em: 01 jul. 2020.

VALENTE, W. R. O ensino intuitivo de arithmetica e as Cartas de Parker. In: CONGRESSO BRASILEIRO DE HISTÓRIA DA EDUCAÇÃO,5., 2008.

Universidade Federal de Sergipe. Anais [...]. Aracaju, 2008. Disponível em: http://sbhe.org.br/novo/congressos/cbhe5/ trabalho_completo.php?id=528 . Acesso em: 05 mai. 2020.

VALENTE, W. R. Processos de Investigação Histórica da Constituição do Saber Profissional do Professor que Ensina Matemática. Acta Scientiae, Canoa, v. 20, p. 377-385. 2018. DOI: https://doi.org/10.17648/acta.scientiae.v20iss3id3906.

VALENTE, W. R. et al. A Matemática na Formação de Professores e no Ensino: processos e dinâmicas de produção de um saber profissional, 1890-1990. Projeto de Pesquisa. São Paulo: FAPESP, 2017. Disponível em:

http://bv.fapesp.br/pt/auxilios/98879/a-matematica-na-formacao-de-professores-e-noensino-processos-e-dinamicas-de-producao-de-um-saber-p/. Acesso em: 05 mai. 2020.

ZANATA, B. A. O legado de Pestalozzi, Herbart e Dewey para as práticas pedagógicas escolares. Revista Teoria e Prática da Educação, v. 15, n. 1, p. 105-112, jan./abr. 2012. DOI: https://doi.org/10.4025/tpe.v15i1.18569.

Recebido em julho de 2020. Aprovado em novembro de 2020. 